\title{
Study on Multimedia Teaching and the Reform of College Physical Education: Evaluation of Teaching Effect
}

\author{
Lifeng Xu \\ Department of Physical Education, Xi'an University of Posts \& \\ Telecommunications, Xi'an 710061, Shaanxi, China
}

\begin{abstract}
The development of information technology has changed the traditional teaching methods and means, especially in physical education. Twenty-first century will be the era of multimedia, multimedia technology will change the teaching mode, content and methods, ultimately lead to the fundamental reform of whole educational theory and education system. In this paper, author evaluate the effect of multimedia teaching by using questionnaire survey, result shows that more than 55\% students in physical education were satisfied with the multimedia teaching, however, multimedia teaching has low performance in teaching method and interaction. Therefore, the university should strengthen the professional development of physical education teachers in information technology teaching, set up corresponding information teaching service center, providing digital resources, network curriculum development and instructional design, comprehensively improve the teaching ability of multimedia teaching.
\end{abstract}

Keywords: Multimedia technology; physical teaching; education reform; teaching effect

\section{Introduction}

With the rapid development of science and technology, it provides a strong material foundation for education and teaching. More and more modern high-tech achievements in education, teaching, training, the education has changed a lot. Making use of advanced scientific and technological means to make all the theories and methods of improving the teaching effect, and to transfer and permeate the teaching of physical education and training. To improve the overall effect of teaching and training is an urgent task facing the teaching of physical education[1]. With the help of the theory and method to improve the current situation of physical education teaching and training, it is also a new task in front of every physical education teacher. Due to the wide application of multimedia technology, to improve the level and quality of work, the reform of traditional teaching and training methods and means, has opened up an unprecedented new areas.

Physical education is the main theme of the sports work in Colleges and universities, and it is an important part of training the all-round development of talents. Optimizing the process of physical education teaching, improving the efficiency of physical education teaching is an important goal of the pursuit of physical education, but also the fundamental way to improve the quality of physical education. Teaching means is the main measure to achieve the teaching objectives, the use of advanced teaching methods multimedia technology as an auxiliary means of college physical education, is the inevitable trend of the reform of college sports in twenty-first Century[2]. Twenty-first Century will be the era of multimedia, multimedia technology will change the teaching mode, teaching content, teaching methods, teaching methods, and ultimately lead to the whole educational theory, teaching theory and even the fundamental reform of the education system[3]. Therefore, college physical education should take the initiative to seize the opportunity, to adapt to the needs of the community, to change the traditional 
teaching concepts, modern teaching means into the P. E. teaching, enrich the teaching content of physical education, stimulate the interest of students on the movement of knowledge and skill learning, broaden the horizons of knowledge, to improve the quality of teaching, promote the development of physical education. Multimedia technology is a technology to disseminate information to users in the form of image, sound, animation and text. It is not only a large amount of information and complexity to simplicity, from difficult to easy, static to dynamic, peacetime the teacher indistinct, is not easy for students to grasp to understand knowledge, show at a glance in front of students; can also in various forms, from different angles and different aspects and multi information, multi view, full range, dynamic expression of focal and difficult points in teaching; add pictures, images, animation and other a variety of visual and audio information, to help understand the teaching of clarifying the emphasis and difficulty, vividly inspired the enthusiasm of students learning, concentration, culture observation, thinking and imagination.

Due to the change of knowledge, the traditional sports teaching cannot meet the requirements of modern physical education. How the organic combination of a variety of modern teaching media and traditional teaching means, especially the multi computer media technology into the physical education classroom, in order to meet the requirements of modern physical education teaching is an important issue facing the reform of physical teaching. Although the current multimedia technology in the field of sports teaching is becoming more and more popular, but sports teaching process in the application of multimedia technology into the, due to the PE Teachers' computer level, modern education technology theory and practice level, making multimedia application level is not high and a lot of theoretical principles and methods are not very accurate[4]. The in view of the problems of the current multimedia technology in sports teaching are proposed the question, the multimedia technology in the teaching of physical education, especially the application in the teaching of physical education in Colleges and universities of comprehensive study of systematic and scientific.

\section{Literature Review}

\subsection{Multimedia Technology}

Media is often refers to people familiar with the news media, such as newspapers, television, magazines, movies, radio, etc., they sound, graphics, images, text, video signal as a medium to we provide all kinds of information. In the field of computer, refers to the most basic technology and means of information transmission and storage. It includes two kinds of meaning, a is entities information storage, such as disk, CD, tape, $U$ disk, semiconductor memory, the Chinese often translated as the medium; another is refers to the transmission of information carrier, such as numbers, text, sound, graphics, images and other Chinese translation for the media[5]. According to the definition of the International Telegraph and Telephone Consultative Committee and the International Telecommunications Standards (TSS) recommendations, the media has the following 5 major types:

1) Perception Medium: refers to the direct effect on people's sense organs, so that people can directly feel the media. Such as language, music, all kinds of sounds in nature, all kinds of images, animation, text.

2) Medium Representation: refers to the media for the transmission of the media and human research out of the media. With this kind of media, it can be more effective to store the sense of media or to feel the media from one place to another place to be sent to another. Words such as encoding, telegraph code, bar code. 
3) Presentation Medium: refers to the communication between the electrical signals and the feeling of media generated between the conversions of the media. Such as input and output facilities, keyboard, mouse, monitor, printer.

4) Storage Medium: refers to the media used to store some kind of media, such as paper, tape, disk and CD.

5) Transmission Medium: refers to the media for the transmission of certain media. Commonly used in such as telephone lines, cables, optical fiber, radio waves, infrared.

People generally believe that the "multimedia" refers to at the same time acquisition, processing, editing, storage and display of two or more different types of information media technology, the information media including: text, sound, graphics, images, animation, video and other. In this sense, we often say that the multimedia is ultimately attributed to a technology [6]. In fact, it is because of the substantial progress of computer technology and digital information processing technology, which makes us have the ability to deal with multimedia information today, which makes the "multimedia" become a reality. So, what we are saying is "multimedia", often not to refer to a variety of media itself, but mainly refers to the processing and application of a set of technology. As a result, the "multimedia" is often used as a synonym for multimedia technology [7]. It should also be noted that the multimedia technology is now talking about people often linked to the computer, which is due to the computer's digital and interactive processing capabilities, has greatly promoted the development of multimedia technology. It can be regarded as a new technology or product that is formed by the technology of advanced computer technology and the technology of video, audio and communication.

Multimedia technology can also be understood is the multimedia computer technology, refers to is the use of computer technology to deal with many kinds of media information, such as text, sound, graphics, image, animation, video, many kinds of media information to establish a logical connection, and organically integrated together and become a interactive, new computer system technology. Which emphasizes the multimedia technology is a computer processing technology; a kind of information processing technology and a kind of human-computer interaction technology; it is a variety of media and application of integrated technology.

\subsection{Physical Education}

In different historical periods, the word "teaching" has different understanding of the concept of teaching because of its broad sense and narrow sense, as well as the differences in emphasis. From the classification of educational level, the teaching of teaching of teaching of preschool education, general education and higher education; teaching from the classification of educational category, and the teaching of school education, family education and social education teaching, and so on[8]. Generalized teaching refers to all informal form and occasion, the content of the experience of teaching and experience activity, while the narrow sense definition of teaching is in this specialized school places for the training of the younger generation of teaching activities. We here deals with teaching refers to the teaching activities in schools, we give its definition is: teaching is to guide the students in teacher, purposeful, planned and systematically learning scientific and cultural knowledge and basic skills, at the same time, the development intelligence and physical strength, and form correct world outlook and good quality process. Teaching is the basic way to realize the aim of school education. Sports teaching and other subjects teaching is a purposeful, planned, organized the students to teach knowledge and skills, intellectual and physical development cultivate virtues and formation of personality education process, but also its particularity, it is one of the targets of school physical education, the way to achieve, a branch of education is not only a science, is also the sports science a part. Encyclopedia of China in to the sports teaching concept is defined like this: education in accordance with the plan and syllabus 
of physical education, by the teacher to the students teach sports knowledge, technology and skills, can develop the student body, and enhance physical fitness, ideological, moral, will and the quality of education for students at the same time. It is a purposeful, planned, organized education process.

Sports teaching and course teaching in common and different points, their common point is: is the bilateral activities of teachers and students, in the process of teachers to play a leading role; teachers should have a purpose in a planned way to guide the students to learn and to teach them some knowledge, skills, cognitive ability development of the students, training students' personality and ideological and moral[9]. Different points: the teaching of other courses mainly by teacher's lectures and demonstrations, through their own thinking activity process, understand and master teachers to impart knowledge on science and culture, and physical education not only requires the teachers explanation, the demonstration also need to students' bodies directly involved in practice to master the skills, technology. In this process, students not only think activities, but also physical activity. Other course teaching is the development of students' intelligence, physical education is not only to develop the students' intelligence, but also must develop students' physical strength. Compared with other culture teaching, physical education has the following characteristics:

1) Teaching goals: the main goal of physical education teaching is impart selectivity of sports knowledge, technology and skills, so that students understand the sport for self perfection and in the extended play an important role in the process of life, cultivate interest and ability of students' self exercise, promote physical development, physical fitness[10]. The important goal of culture teaching is to teach students the cultural science knowledge, develop intelligence, and cultivate creative thinking ability.

2) Teaching content: physical education to teach sports technology, skills as the main content, its fundamental purpose is to enhance the physical fitness of students. Students learn physical education this course, the ultimate goal is to exercise the body, the construction of the motherland. Exercise is the main means of a variety of sports. This determines the main content of the course of sports is the technology of sports. Through repeated practice and into skills, master the exercise method, at the same time, to learn sports science knowledge, in order to guide the physical exercise. To compare the teaching content of physical education curriculum and other cultural courses and other cultural curriculum teaching content is dominated by the cultural knowledge of the course, students master the cultural knowledge, in the future for the production practice and social practice. And physical education is the technical teaching, mainly used for physical practice. Compared to the two phases, it clearly reflects the characteristics of physical education content.

3) Organization of teaching: physical education is generally performed in the stadium, and some are even in the outside environment of, development of teaching environment, teaching space is larger, and the use of a variety of equipment in different site physical exercise. This teaching is carried out in the process, adolescent physical and psychological are in growth and development process, energetic, strong thirst for knowledge and with the class students up to a dozen, dozens of people, male and female students are different in character, quality level, activities of different, environmental interference and venues and facilities and other constraints, these factors determines the diversity of physical education teaching organization and complexity of the organization form. The teaching of other cultural courses in the classroom or laboratory, the teaching environment is relatively closed, less interference, teachers and students are relatively static, so the organization of teaching is relatively simple. 


\section{Research Design}

\subsection{Questionnaires}

For a comprehensive and detailed understanding of the current situation of multimedia teaching quality in Colleges and universities, we designed three different questionnaires for teachers, students and supervisors. Three copies of the questionnaire design contains closed and open type two, and the design of a number of similar problems, to seek teacher, student and expert supervision investigation on the same issue on which views of each card, better get real information of consistency. In this study, we choose Xi'an University of Posts \& Telecommunications as the research object; take the college stratified sampling method to determine the object of investigation (teachers and students). The size of the teachers sample is $150-200$, and the students sample size is 300400. Valid questionnaires to students mainly take the form of recycling site to extend, teachers and teaching supervision experts questionnaire mainly take email and on-site recycling combined form of payment, recovered a total of 153 teachers, 367 students and teaching expert supervision, efficiency of $89.5 \%, 90.6 \%$ and $100 \%$ respectively.

\subsection{Multimedia Physical Education Characteristics}

Sports teaching requires a strong demonstration: knowledge of the physical education teaching is mostly a technical movements, the teacher can through text, language, pictures, audio and video form to teach, but most of them are static form and with a single sensory stimulation of the students, and through multimedia teaching demonstration can make students a variety of sensory stimuli; enable students to more easily accept the teaching content; teaching effect is good, convenient for students in cognition, memory and understanding. According to the statistical analysis of educational psychologists, the total amount of information obtained by audio-visual information for 3 of $94 \%$ days after $70 \%$ days can remember, are far more than other modes of transmission. In the teaching at the same time to mobilize the audio-visual function, can significantly improve the students' learning efficiency and promote their motor skills, observation, observation, and then observe". Will be an action the whole process and hard points in turn through a variety of means to show in front of the students, teachers can easily explain the technical essentials decomposition, demonstrates the whole movement process, and thus seize the action key part, focus and difficult to break the rigid structure of class, effectively save the time of physical education, reducing the repeated explanation, and leads to the phenomenon of student movement error and increase the exercise time, improve the quality of teaching.

Physical education learning way of iconicity: Students on the image of the thing memory is stronger, and in learning, for theory is often associated with their sports practice combination, this way of thinking is suitable for multimedia teaching, with the aid of in multimedia rich and colorful combination, with its intuitive, vivid, graphic and luxuriant, beautiful colors, provide novel, peculiar, interesting, according to the teaching material to stimulate students' a variety of sensory and attract students attention, stimulate students' interest, arouse students' enthusiasm.

The richness of the content of Physical Education: Physical education includes theory and practice. Practical courses include track and field, ball games, martial arts, etc.. The theory course includes the school physical education, the introduction of physical education, sports physiology, sports psychology, sports technology theory and so on. These contents are rich in pictures, text, images and other information, which gives a full material guarantee for multimedia teaching.

Socialization of sports information: In today's society has entered the information society, people pay more and more attention to human health, people demand for sports is very strong. Therefore, about sports on TV, audio, pictures and CD for people provides a great deal of sports information, but also for the sports multimedia teaching provided rich 
material and, with the development of technology, audio-visual technology perfect, the audio and video materials burn disc more and more low cost, provide technical support and guarantee for the sports multimedia teaching resource rich, at the same time, make the person of multimedia courseware and design become possible.

\subsection{Advantages of Multimedia Technology in Physical Education}

Multimedia technology will physical education curriculum in the form of text, graphics, combined with audio, video and animation in one, three-dimensional display of the teaching content and form and means of expression is more rich and flexible, fully reflects its unique advantages.

1) Updated the concept of Physical Education: the application of multimedia technology in physical education teaching, change the traditional PE teaching to "teaching" as the center of teaching mode, teachers in the use of modern multimedia teaching means to teach, and at the same time, using in human-computer interaction and students to communicate with each other, to stimulate the students sense of participation, and reflects the sports multimedia teaching is based on "learning" as the center of teaching ideology. It has a great effect on the change of the teaching methods of physical education and the change of practice, as well as the change of the way of thinking of students' learning sports knowledge and skills.

2) To improve the quality of teaching: the traditional PE teaching theoretical courses in teachers to teach primarily, supplemented with pictures, charts display the form. The course mainly depends on the teacher's explanation and demonstration, due to the limitations of subjective and objective conditions, a lot of technical movement's demonstration difficult to achieve complete standards, norms, and students is difficult in a short period of time to form correct action concept, and students can only rely on teacher feedback. The teaching effect can be imagined. The implementation of multimedia teaching has greatly changed the situation, abstract physical concept with the image to image; the action of high difficulty can be simulated by computer. And for the complex structure, the speed of the action of the explanation and demonstration, the effect is more significant. By using the multimedia technology, we can use the slow motion to make the students aware of this series of actions, form the concept, and grasp the essentials, easy to imitate and master, and greatly improve the teaching effect and efficiency.

3) Improve the students' physical learning effect: multimedia technology can stimulate the body's vision, hearing and a variety of sensory system, the brain of different functional areas alternating activity, make the learning content vivid, strong interest, intuitive and easy to understand. The means of expression in multimedia technology, the integrated use of graphics, animation, music, flash, color, font, and so on, "colorful", "sound and Mao", enhance the content of PE teaching art expressive force and strong appeal, active classroom atmosphere. Especially the multimedia teaching information embodied in the power of beauty and art beauty, body harmonious beauty, so that students truly realize the sports function and character of social value, stimulate the college students' knowledge of desire and they love sports, school physical education learning enthusiasm, effectively improve the students' learning interest and the sports classroom teaching quality.

\section{Empirical Analysis}

\subsection{Analysis of the Use of Multimedia Teaching Environment}

The multimedia teaching environment mentioned here refers to the multimedia facilities and equipment used by teachers in the classroom during class. Table 1 shows each class will be used, frequently used and other indicators are expressed by the teachers 
on the use of a multimedia environment factors, we call it tendency. From table 1, we can see that the PPT file has a tendency to be as high as $95 \%$ for each class, while the TV and radio are "basically not". "Sample variance" indicates a tendency of concentration, the greater the value, the higher the degree of concentration, and vice versa. From table $1 \mathrm{can}$ be seen, sample variance order from big to small is as follows: the PPT file, radio, television, network, play equipment, digital booth, visible teachers use the PPT file the most consistent, and for the digital booth, may because of the teachers to the understanding of the biggest divergence.

Table 1.Analysis of the use of Multimedia Teaching Environment

\begin{tabular}{|c|c|c|c|c|c|c|c|c|c|c|c|c|}
\hline \multirow{2}{*}{$\begin{array}{c}\text { Multimedia } \\
\text { types }\end{array}$} & \multicolumn{2}{|c|}{$\begin{array}{c}\text { Every class } \\
\text { will use }\end{array}$} & \multicolumn{2}{c|}{$\begin{array}{c}\text { Frequent } \\
\text { use }\end{array}$} & \multicolumn{2}{c|}{ commonly } & \multicolumn{2}{c|}{ Less use } & \multicolumn{2}{c|}{$\begin{array}{c}\text { Basic need } \\
\text { use }\end{array}$} & \multirow{2}{*}{$\begin{array}{c}\text { Sample } \\
\text { variance }\end{array}$} & \multirow{2}{*}{ Skewness } \\
\cline { 2 - 15 } & No. & Ratio & No. & Ratio & No. & Ratio & No. & Ratio & No. & Ratio & 1762.5 & 2.22 \\
\hline PPT file & 37 & 95 & 2 & 5 & 0 & 0 & 0 & 0 & 0 & 0 & 1762.5 \\
\hline $\begin{array}{c}\text { Digital } \\
\text { booth }\end{array}$ & 10 & 26 & 3 & 8 & 5 & 12 & 10 & 26 & 11 & 28 & 86.0 & -0.68 \\
\hline network & 2 & 5 & 3 & 8 & 4 & 9 & 15 & 39 & 15 & 39 & 303.0 & 0.58 \\
\hline $\begin{array}{c}\text { Play } \\
\text { equipment }\end{array}$ & 5 & 13 & 3 & 8 & 4 & 10 & 17 & 43 & 10 & 26 & 214.5 & 1.24 \\
\hline Television & 0 & 0 & 0 & 0 & 9 & 23 & 2 & 5 & 28 & 72 & 934.5 & 1.77 \\
\hline radio & 0 & 0 & 0 & 0 & 10 & 25 & 1 & 3 & 28 & 72 & 954.5 & 1.69 \\
\hline
\end{tabular}

The "skewness" in Table 1 indicates the use of a multimedia in the distribution of the sequence from every class must be used to basic. If the skewness is positive, which means the majority concentrated on the left, should extend to the right, it is called positive skewness; on the contrary, if the skewness is negative, it should be extended to the left, and said for the negative skewness. The magnitude of the absolute value indicates the degree to which the tendency is adjacent to the two ends. Table 1 in addition to the digital booth as a negative skewness, the rest are positive skewness, PPT file of the degree of deviation of 2.22, a high degree of concentration and a strong positive tendency. The analysis shows that the elements of PPT excessive dependence are the main characteristics of the use of physical education teaching in multimedia environment factors, according to Mayer et al proposed modality principle should increase other teaching channel.

Table 2. The Usage of Multimedia Teaching File

\begin{tabular}{|c|c|c|c|c|c|c|c|c|c|c|}
\hline \multirow{2}{*}{ file type } & \multicolumn{2}{|c|}{$\begin{array}{c}\text { Every class will } \\
\text { use }\end{array}$} & \multicolumn{2}{c|}{$\begin{array}{c}\text { Frequent } \\
\text { use }\end{array}$} & \multicolumn{2}{c|}{ commonly } & \multicolumn{2}{c|}{ Less use } & \multicolumn{2}{c|}{$\begin{array}{c}\text { Basic need } \\
\text { use }\end{array}$} \\
\cline { 2 - 13 } & No. & Ratio & No. & Ratio & No. & Ratio & No. & Ratio & No. & Ratio \\
\hline Audio file & 1 & 3 & 4 & 10 & 5 & 13 & 18 & 46 & 11 & 28 \\
\hline video file & 2 & 5 & 8 & 21 & 4 & 10 & 18 & 46 & 7 & 18 \\
\hline Text file & 22 & 56 & 9 & 23 & 3 & 8 & 2 & 8 & 3 & 5 \\
\hline Graphic file & 15 & 39 & 14 & 36 & 2 & 4 & 5 & 13 & 3 & 8 \\
\hline Table curve & 9 & 23 & 17 & 44 & 2 & 4 & 8 & 21 & 3 & 8 \\
\hline
\end{tabular}

Obviously, the use of audio files and video files is not optimistic. Every class will use and frequently use two tendency index together, audio file utilization rate is only $13 \%$, $26 \%$ of the video file, and text file, a graphics file "and" form curve tendency respectively $79 \%, 75 \%$ and $67 \%$, the concentration degree is high, which in a large extent increased visual effect, the results show that: sports teaching PPT file content is rich, but only limited to PPT file as a platform, but also the lack of the content is more rich and independent video, audio and form curve file organization teaching. 


\subsection{Analysis of Multimedia Teaching Effect}

Multimedia teaching effect evaluation can be carried out from two aspects: teachers and students, this article from the former, the specific situation in table 3. From table 3, we can see that the teacher's view of each effect is more consistent, teachers have a positive attitude to the teaching effect of multimedia, but teachers do not think that the effect of multimedia teaching has been played to the extreme. Under the strong impact of education informatization, although minority has been used in the teachers teaching material and teaching and writing of multimedia have a fear, scholars have expressed doubts to an overemphasis on the role of multimedia teaching, but even to computer and network and not the interests of teachers cannot avoid the use of multimedia. Through investigation and analysis, our evaluation is two aspects. First, the multimedia is a good teaching method has been widely welcomed by the majority of teachers; secondly, multimedia teaching methods have drawbacks, mainly for three missing: lack of some important multimedia environmental factors, students' learning initiative of deletion and Application Countermeasures of missing.

Table 3.Self Rating Scale of Teachers' Multimedia Teaching Effect

\begin{tabular}{|c|c|c|c|c|c|c|c|c|c|c|}
\hline \multirow{2}{*}{ Teaching purpose } & \multicolumn{2}{|c|}{ very good } & \multicolumn{2}{c|}{ preferably } & \multicolumn{2}{c|}{ commonly } & \multicolumn{2}{c|}{ not good } & \multicolumn{2}{c|}{ waiver } \\
\cline { 2 - 14 } & No. & Ratio & No. & Ratio & No. & Ratio & No. & Ratio & No. & Ratio \\
\hline $\begin{array}{c}\text { Expanding } \\
\text { knowledge }\end{array}$ & 13 & 33 & 20 & 51 & 4 & 10 & 0 & 0 & 2 & 6 \\
\hline Accumulate data & 10 & 26 & 16 & 41 & 4 & 10 & 0 & 0 & 9 & 23 \\
\hline $\begin{array}{c}\text { Additional } \\
\text { content }\end{array}$ & 10 & 26 & 24 & 62 & 2 & 5 & 0 & 0 & 3 & 7 \\
\hline Intensive study & 7 & 18 & 15 & 39 & 8 & 21 & 0 & 0 & 9 & 22 \\
\hline $\begin{array}{c}\text { Reference } \\
\text { guidance }\end{array}$ & 7 & 18 & 21 & 54 & 5 & 13 & 0 & 0 & 6 & 15 \\
\hline $\begin{array}{c}\text { Learning } \\
\text { initiative }\end{array}$ & 6 & 15 & 15 & 39 & 7 & 18 & 2 & 5 & 9 & 23 \\
\hline Interaction & 6 & 15 & 22 & 56 & 6 & 15 & 0 & 0 & 5 & 14 \\
\hline $\begin{array}{c}\text { Sense of } \\
\text { innovation }\end{array}$ & 4 & 10 & 16 & 41 & 7 & 18 & 2 & 5 & 10 & 26 \\
\hline
\end{tabular}

Among teachers, students and experts, the overall evaluation of multimedia teaching is the highest degree of satisfaction is the teacher, followed by the steering specialist. In contrast, students' satisfaction evaluation is much lower. From the point of view of their mean, overall assessment of the effect of multimedia teaching "very satisfied" and the proportion of "satisfied" only reached $55.9 \%$ of and nearly $4 \%$ the proportion of "say not clear" and "not satisfied" (see Table 4) that despite the multimedia teaching has become the normalization of university teaching for many years, but overall teaching effect is not very satisfactory.

Table 4. Satisfaction Evaluation of the Effect of Multimedia Teaching

\begin{tabular}{|c|c|c|c|c|c|}
\hline & Very satisfied & satisfied & commonly & dissatisfied & Very unsatisfied \\
\hline teacher & $4.6 \%$ & $69.9 \%$ & $22.2 \%$ & $3.3 \%$ & $0 \%$ \\
\hline student & $3.5 \%$ & $39.8 \%$ & $43.1 \%$ & $12.5 \%$ & $1.1 \%$ \\
\hline expert & $0 \%$ & $50 \%$ & $50 \%$ & $0 \%$ & $0 \%$ \\
\hline mean value & $2.7 \%$ & $53.2 \%$ & $38.4 \%$ & $5.3 \%$ & $0.4 \%$ \\
\hline
\end{tabular}

The teacher's multimedia teaching segments for "technology", "curriculum design", "teaching method, five dimensions of" teacher-student interaction "and" resource design evaluation, found that students for teachers of the technical level of satisfaction evaluation 
was highest close to $70 \%$, the satisfaction of "course content design and resource design also at around 60\%, and assessment of" satisfaction "of" teaching method "and" teacherstudent interaction "relatively low," not satisfied "evaluation is in five dimensions reached the highest, respectively is $16.6 \%$ and $22.6 \%$, far higher than the other dimensions, as shown in Table 5.

Table 5.Students Overall Evaluation of Multimedia Classroom Teachers

\begin{tabular}{|c|c|c|c|c|c|}
\hline & $\begin{array}{c}\text { Very } \\
\text { satisfied }\end{array}$ & satisfied & commonly & dissatisfied & $\begin{array}{c}\text { Very } \\
\text { unsatisfied }\end{array}$ \\
\hline technical level & $13.4 \%$ & $55.6 \%$ & $24.5 \%$ & $6.5 \%$ & $0 \%$ \\
\hline content design & $8.7 \%$ & $52.3 \%$ & $29.4 \%$ & $9.0 \%$ & $0.5 \%$ \\
\hline $\begin{array}{c}\text { teaching } \\
\text { method }\end{array}$ & $6.5 \%$ & $48.0 \%$ & $34.1 \%$ & $10.1 \%$ & $6.5 \%$ \\
\hline $\begin{array}{c}\text { Interaction } \\
\text { Resource } \\
\text { design }\end{array}$ & $6.8 \%$ & $39.2 \%$ & $31.3 \%$ & $20.7 \%$ & $1.9 \%$ \\
\hline
\end{tabular}

Further analysis revealed that although the technology level of students of teachers' evaluation of maximum, however, they are still generally agreed that teachers of multimedia courseware do pretty much, accounted for only $40 \%$, more and more " " is the basic text "accounted for 59.4\%. Two is the teacher's teaching method is relatively simple, nearly half of the teachers in class more frequently to PPT. Three is the teacher-student interaction, there is always the proportion of teachers and students in the classroom is only $7.6 \%, 52.3 \%$ of the classroom teachers and students interact occasionally, and $5.7 \%$ of the multimedia classroom has never been teacher-student interaction. And the survey showed, in the multimedia teaching, most attracts the attention of student's first teachers, teaching content and teaching method, followed by the language art related media resources and teachers, four percentage respectively $34.3 \%, 25.9 \%, 20.2 \%$ and $12.5 \%$, and PPT itself attractive to students only accounted for $6.9 \%$. This shows that the design of teaching content and teaching method is the most cores in the multimedia classroom teaching, and teachers should not blindly pursue the technical realization of PPT effect.

\section{Conclusion}

Based on the above findings and analysis, we found that although the current multimedia course in Colleges and universities to commence rate reached a high level, but the students overall evaluation of college multimedia teaching effect satisfaction results is still not optimistic. The existing problems are mainly reflected in the digital teaching system update lag, multimedia courseware quality overall is not high, the number of curriculum resources construction and other external factors. Internal influence factors reflect the outstanding problems mainly is the lack of teaching design ability of teachers' information, the lack of the theory of multimedia teaching, the single teaching method and so on. Issues related to the investigation exposed, combined with the teacher open questionnaire to collect about improving the multimedia teaching advice, we conclude the improve today's university multimedia teaching quality, out of the current plight of three possible paths.

First is to strengthen the construction of digital resources and teaching support platform, from the traditional single multimedia teaching thinking to the information teaching environment system planning. At present, the multimedia classroom still in ten years ago projection and screen equipment, lack of corresponding digital resources, curriculum platform and network collaborative teaching support platform, many classrooms is not even on the network, the teacher's multimedia teaching limited to display in the PPT courseware, information of teaching methods and means behind even 
in many primary and secondary schools. Therefore, from the angle of human computer engineering to transform the multimedia teaching terminal at the same time, strengthen the related digital platform and learning service construction. It is urgent to set up and transform a number of collaborative classroom, intelligent classroom and digital interactive classroom, which is suitable for collaborative, problem, research and other modern universities. Second is to strengthen the training of teachers' information teaching ability, and promote the deep integration of information technology and university curriculum teaching. According to the survey, as colleges and universities have a large part of the teachers is non educational background, have not received teacher education courses, to the college directly walked to the lectern, education science, especially a serious lack of knowledge of teaching information. Many teachers will be multimedia teaching only as PPT courseware production, teaching with the feeling, information technology curriculum design knowledge sources are mostly rely on self.

Therefore, the universities should be to strengthen the professional development of teachers in information technology teaching ability to improve the support, set up corresponding information teaching service center, provide digital resources, network curriculum development and instructional design of diagnosis, service and guidance, teachers teaching in information technology can force training into the system of university teachers professional ability construction plan, establish outstanding teachers of the course case base and the corresponding sharing mechanism, improving teachers' teaching ability of the information. Third is to strengthen the theoretical and practical research on School-based information education, to promote the quality of information technology support to enhance the quality of teaching to provide a reliable source of wisdom. Survey shows that university teachers for the help of the education of the class to help students agree not high, because they did not find the number of available knowledge". On the surface of multimedia teaching is the change of teaching presentation mode, but it actually points to the innovation of teaching idea, method and design level. How to make full use of multimedia and other information technology and resources to help learners construct experience, explore and think of learning space is the core problem of multimedia teaching should be solved. However, the lack of the research on the theory of multimedia teaching has greatly influenced the improvement of the quality of classroom teaching in universities. Therefore, strengthening of technical support, in order to learn is the basis of curriculum school-based teaching research and exploration to research and promote education, create more university teachers "available" instructional design theory is out of university multimedia teaching present difficulties, from the surface of the deep to enhance classroom teaching quality in Colleges and universities will be created by the diameter.

\section{References}

[1] A.K.Kim and J.Davies, "A teacher's perspective on student centred learning: Towards the development of best practice in an undergraduate tourism course", Journal of Hospitality, Leisure, Sport \& Tourism Education, Vol.25,(2014),pp. 6-14.

[2] M.Hu, S.Xu, "Research of Multimedia Teaching on Principles of Management",IERI Procedia, Vol.2, (2012), pp.666-670 .

[3] C.Krstev, and A.Trtovac, "Teaching Multimedia Documents to LIS Students", The Journal of Academic Librarianship, Vol.40, No.2,(2014), pp.152-162.

[4] M.Sigala, "Investigating the role and impact of geovisualisation and geocollaborative portals on collaborative e-learning in tourism education",Journal of Hospitality, Leisure, Sport \& Tourism Education, Vol.11,(2012), pp.50-66.

[5] C. wei, Y.tao, "Application of Multimedia-Aided Project-Teaching Mode in Cultural Education", IERI Procedia, Vol.2, (2012), pp.538-542.

[6] W.Dai, L.Fan, "Discussion about the Pros and Cons and Recommendations for Multimedia Teaching in Local Vocational Schools",Physics Procedia, Vol.33, (2012), pp.1144-1148.

[7] H.Janta and P.Lugosi, "Migrant networks, language learning and tourism employment",Tourism Management, Vol.33, No. 2,(2012), pp.431-439. 
[8] C.Zhang, X.Chen, "Use of Multimedia in Gross Infective Pathogen Experimental Teaching”, Procedia Engineering, Vol.37, (2012), pp.64-67.

[9] S.Jian-hua, L.hong, "Explore the Effective Use of Multimedia Technology in College Physics Teaching",Energy Procedia, Vol.17, (2012), pp.1897-1900.

[10] Y.Huang and S.Backman, "Experiencing student learning and tourism training in a 3D virtual world: An exploratory study",Journal of Hospitality, Leisure, Sport \& Tourism Education, Vol.13, (2013), pp.190201.

\section{Authors}

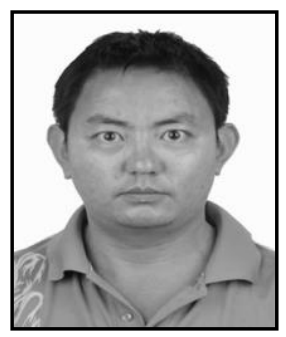

Xu Li-Feng, He is now a Lecturer in Department of Physical Education, Xi'an University of Posts \& Telecommunications, Xi' an Physical Education University, China .His research interest include physical education and training. Publications more than 10 papers published. He has teaching experience of 25 years, had completed four scientific research projects. 
International Journal of Security and Its Applications

Vol. 10, No. 2 (2016) 